\title{
Influence of steep Trendelenburg position on postoperative complications: a systematic review and meta-analysis
}

\author{
Satoshi Katayama ${ }^{1,2}$ (D) Keiichiro Mori ${ }^{1,3} \cdot$ Benjamin Pradere $^{1} \cdot$ Takafumi Yanagisawa $^{1,3} \cdot$ Hadi Mostafaei $^{1,4}$. \\ Fahad Quhal ${ }^{1,5} \cdot$ Reza Sari Motlagh ${ }^{1,6} \cdot$ Ekaterina Laukhtina ${ }^{1,7} \cdot$ Nico C. Grossmann ${ }^{1,8}$. Pawel Rajwa ${ }^{1,9}$. \\ Abdulmajeed Aydh ${ }^{1,10} \cdot$ Frederik König $^{1,11}$ - Pierre I. Karakiewicz ${ }^{12} \cdot$ Motoo Araki $^{2}$ - Yasutomo Nasu ${ }^{2}$. \\ Shahrokh F. Shariat ${ }^{1,7,13,14,15,16,17}$
}

Received: 12 October 2021 / Accepted: 21 December 2021 / Published online: 31 December 2021

(c) The Author(s) 2021

\begin{abstract}
Intraoperative physiologic changes related to the steep Trendelenburg position have been investigated with the widespread adoption of robot-assisted pelvic surgery (RAPS). However, the impact of the steep Trendelenburg position on postoperative complications remains unclear. We conducted a meta-analysis to compare RAPS to laparoscopic/open pelvic surgery with regards to the rates of venous thromboembolism (VTE), cardiac, and cerebrovascular complications. Meta-regression was performed to evaluate the influence of confounding risk factors. Ten randomized controlled trials (RCTs) and 47 nonrandomized controlled studies (NRSs), with a total of 380,125 patients, were included. Although RAPS was associated with a decreased risk of VTE and cardiac complications compared to laparoscopic/open pelvic surgery in NRSs [risk ratio (RR), 0.59; 95\% CI 0.51-0.72, $p<0.001$ and RR 0.93; 95\% CI 0.58-1.50, $p=0.78$, respectively], these differences were not confirmed in RCTs (RR 0.92; 95\% CI $0.52-1.62, p=0.77$ and RR 0.93 ; 95\% CI $0.58-1.50, p=0.78$, respectively). In subgroup analyses of laparoscopic surgery, there was no significant difference in the risk of VTE and cardiac complications in both RCTs and NRSs. In the meta-regression, none of the risk factors were found to be associated with heterogeneity. Furthermore, no significant difference was observed in cerebrovascular complications between RAPS and laparoscopic/ open pelvic surgery. Our meta-analysis suggests that the steep Trendelenburg position does not seem to affect postoperative complications and, therefore, can be considered safe with regard to the risk of VTE, cardiac, and cerebrovascular complications. However, proper individualized preventive measures should still be implemented during all surgeries including RAPS to warrant patient safety.
\end{abstract}

Keywords Trendelenburg position $\cdot$ Complication $\cdot$ Thrombosis $\cdot$ Cardiac $\cdot$ Meta-analysis

\section{Introduction}

During the past few decades, laparoscopic surgery has become the standard procedure in many surgical fields. The quest for improvement for both patients and surgeons using technological innovation has led to widespread use of Intuitive Surgical da Vinci surgical system for pelvic surgery [1]. This technology enables better magnified 3D visualization, tremor filtration, and comfortable remote console [2]. With a marked increase in the use of robotic platforms, a multitude of trials have investigated patients' benefits regarding

Shahrokh F. Shariat

shahrokh.shariat@meduniwien.ac.at

Extended author information available on the last page of the article oncologic and perioperative outcomes [1]; despite the efforts of researchers, little to no evidence suggests that robot-assisted pelvic surgery (RAPS) improves complication rates and oncologic outcomes over other procedures [3-6]. In addition to these limited benefits, various potential risk and disadvantages to RAPS are likely to result from the steep Trendelenburg position alone or in combination with pneumoperitoneum. This head-down tilt position has been shown to result in decreased lung volume, lung compliance, functional residual capacity and increased peak airway pressure, leading to postoperative pulmonary complications (PPCs). The prevalence of PPCs is approximately 30\%, and is associated with increased mortality and morbidity rates [7, 8]. Although its clinical significance remains debatable, this non-physiological positioning typically increase the risk 
for several intraoperative hemodynamic and intracranial changes, such as increased cardiac contractility, increased cardiac oxygen consumption, and increased intracranial pressure $[9,10]$. Compared to research on PPCs, whether these intraoperative changes translate into postoperative detrimental effects remains uncertain. Venous thromboembolism (VTE), which consists of deep vein thrombosis (DVT) and pulmonary embolism, and cardiac and cerebrovascular complications are relatively rare but potentially life-threating. A comprehensive assessment of postoperative complications related to the steep Trendelenburg position is needed to establish preventable measures. Thus, we conducted a systematic review and meta-analysis to clarify the effects of steep Trendelenburg position related to RAPS on postoperative complications.

\section{Evidence acquisition}

This study protocol was registered in the International Prospective Register of Systematic Reviews database (PROSPERO CRD: 42021252198).

\section{Literature search}

This systematic review and meta-analysis was conducted according to the Preferred Reporting Items for Systemic Reviews and Met-Analyses (PRISMA) Protocol 2009 checklist, as shown in Supplementary Table 1 [11]. PubMed, Web of Science, and Cochrane Library databases were searched in January 2021 to identify relevant studies examining the role of RAPS compared to laparoscopic and/or open pelvic surgery for patients with common pelvic malignancies, including prostate, bladder, colorectal, endometrial, and cervical cancers. The following terms were used: (prostate OR bladder OR urothelial OR rectal OR colorectal OR colon OR endometrial OR cervical) AND (cancer OR carcinoma)) AND (robotic surgery OR robot-assisted surgery OR Da Vinci) AND (complication OR morbidity). We also checked the reference lists to detect relevant publications.

\section{Inclusion and exclusion criteria}

The population, intervention, comparator, outcome, and study design (PICOS) approach in this study was as follows: patients with pelvic malignancies $(\mathrm{P})$ who underwent RAPS with curative intent in the steep Trendelenburg position (I) were compared with those who underwent open or laparoscopic pelvic surgery $(\mathrm{C})$ in terms of any grade of VTE, cardiac, and cerebrovascular complications $(\mathrm{O})$ in randomized controlled trials (RCTs) and non-randomized controlled studies (NRSs) (S). Only articles written in English were included in the study. To reduce heterogeneity due to the rarity of objective outcomes, comparative studies that enrolled a minimum of 100 patients in each arm were included. Only studies that performed surgery with a curative intent were included. Studies were excluded if they compared with arms using transanal or transvaginal approach, performed surgery for a benign disease or extraperitoneal RAPS was performed as an intervention group. In case of patient positioning was precisely described, studies comparing extraperitoneal vs transperitoneal RAPS were included. The primary endpoint of interest was VTE, and the secondary endpoints were cardiac and cerebrovascular complications, regardless of the complication grade. Initial screening was performed independently by two investigators based on the titles and abstracts of the articles to identify eligible reports. After the first screening, potentially relevant studies were assessed and reasons for exclusion were noted through a full-text review. Any discrepancies were resolved via consensus with co-authors.

\section{Data extraction}

We extracted the following data from the eligible studies: first author's name, publication year, period of patient recruitment, recruitment region, study design, surgical procedure, number of patients, age, sex, body mass index (BMI), American Society of Anesthesiology (ASA) score $\geq 3$, number of advanced malignancy patients, operative time, number of patients who underwent lymph node (LN) dissection, number of LNs removed, estimated blood loss (EBL), blood transfusion rates, length of stay (LOS), and postoperative complications including VTE, cardiac, and cerebrovascular events. Advanced malignancy was defined as $\mathrm{pT} \geq 3$ or pathologic stage $\geq 3$ (in cases where pT stage is not available). All discrepancies regarding data extraction were resolved via consensus with co-authors.

\section{Risk of bias assessment}

Two investigators independently assessed the risk of bias in each study according to the second edition of the Cochrane Handbook for Systematic Reviews of Interventions. We used the RoB for RCTs and the Risk of Bias In Non-randomized Studies of Interventions (ROBINS-I) for NRSs. (Supplementary Tables 2 and 3, respectively).

\section{Statistical analyses}

A meta-analysis was conducted separately for each dichotomous outcome using the risk ratio (RR) and 95\% confidence intervals (CIs). The RCTs were separately analyzed from the NRSs. Continuous variables reported as median and interquartile range were altered to mean and standard deviation (SD) [12]. A random-effects model was applied to represent 
forest plots in meta-analysis of both RCTs and NRSs and 0.5 continuity corrections for 0 cells were applied. Significant heterogeneity was indicated by a $p$ value of $<0.05$ in the Cochran's Q test and a ratio of $>50 \%$ in the $I^{2}$ statistic. Additionally, considering that the development of VTE is multifactorial with clinically considerable heterogeneity, we performed a meta-regression analysis to explore the potential causes of heterogeneity and estimate the effects of age, BMI, comorbidity (ASA score $\geq 3$ ), advanced malignancy, patients who underwent $\mathrm{LN}$ dissection, $\mathrm{LN}$ yields, operative time, EBL, and LOS on VTE event rates. Comorbidity, advanced malignancy, and patients who underwent LN dissection were transformed to categorical variables using a cut-off according to the respective median value of $20.2 \%$, $34.0 \%$ and $72.7 \%$, respectively. In addition, we performed subgroup analyses of patients according to type of surgical procedures (laparoscopic or open pelvic surgery) in VTE and cardiac complications to reduce and evaluate the effects of pneumoperitoneum and other risk factors. Publication bias was evaluated using Egger's test, funnel plots were applied for analyses involving more than ten studies. All statistical analyses were performed using Stata ${ }^{\circledR}$ /MP 14.0 (Stata Corp., College Station, TX, USA); statistical significance was set at $p<0.05$.

\section{Results}

Our initial search identified 2991 publications; and 4 additional studies were added after the latest search. After removing duplicate publications, 409 articles were selected for further assessment. After a full-text review, 57 articles with 380,125 patients were deemed eligible for inclusion and exclusion criteria [4-6, 13-66]. A detailed study selection process is shown in Supplementary Fig. 1. The main characteristics of the included studies are summarized in Table 1 and Supplementary Table 4. A total of 10 RCTs and 47 NRSs were identified, with 31 from North America, 12 from Asia, 10 from Europe, 2 from other region, and 2 from international collaborations. Of them, 115,572 (30\%), $51,978(14 \%)$, and 212,575 (56\%) patients underwent robotassisted, laparoscopic, and open procedures, respectively. A total of 16 (28\%) studies including patients with prostate cancer, 11 (19\%) bladder cancer, 11 (19\%) colorectal cancer, $10(18 \%)$ endometrial cancer, 4 (7\%) uterine cancer, $3(5 \%)$ cervical cancer, and 2 (4\%) gynecologic cancers.

There was no publication bias for NRSs in VTE, cardiac, and cerebrovascular complications according to the funnel plot and Egger's test ( $p=0.79, p=0.76$, and $p=0.79$, respectively) (Supplementary Fig. 1).

\section{VTEs and steep Trendelenburg position}

Seven RCTs comprising 772 patients and 37 NRSs with 168,040 patients provided data on the incidence of VTE. Forest plots (Fig. 1A) revealed that there was no significant difference in RCTs (RR 0.92; 95\% CI 0.52-1.62; $p=0.77$ ), while patients who underwent RAPS had a significantly decreased risk of VTE in NRSs (RR 0.59; 95\% CI $0.51-0.72 ; p<0.001)$ compared to those who underwent laparoscopic or open surgeries. Based on the Cochran's $Q$ and $I^{2}$ tests, no significant heterogeneity was observed in either RCTs ( $p=0.69, I^{2} 0 \%$, respectively) and NRSs ( $p=0.11, I^{2} 23 \%$, respectively). Subgroup analyses based on surgical procedure found that there was no significant difference in laparoscopic pelvic surgery in both RCTs (RR, 0.84; 95\%CI, 0.43-1.62; $p=0.60)$ and NRSs (RR 0.94; 95\% CI 0.66-1.33; $p=0.71$ ) (Fig. 1B); however, there was a statistically significant difference in NRSs (RR 0.53 ; $95 \%$ CI $0.45-0.63 ; p<0.001$ ), but no significant difference in RCTs (RR $0.83 ; 95 \%$ CI $0.46-1.52 ; p=0.55$ ) in open pelvic surgery (Fig. 1C).

\section{Cardiac complications and steep Trendelenburg position}

A total of 5 RCTs comprising 1080 patients and 30 NRSs with 1,361,576 patients provided data on cardiac complications. Forest plots (Fig. 2A) revealed that there was no significant difference in RCTs (RR 0.93; 95\% CI $0.58-1.50 ; p=0.78$ ), while patients who underwent RAPS had a significantly lower risk of cardiac complications (RR 0.77 ; 95\% CI 0.64-0.92; $p=0.004$ ) in NRSs compared to those who underwent laparoscopic or open surgeries. Based on the Cochran's $Q$ and $I^{2}$ tests, no significant heterogeneity was found in RCTs $\left(p=0.56, I^{2} 0 \%\right)$, while there was significant heterogeneity in NRSs $(p<0.001$, $\left.I^{2} 63 \%\right)$. Subgroup analysis based on type of surgical procedure (Fig. 2B) revealed no significant difference between RAPS and laparoscopic surgery in both RCTs (RR 0.79, 95\% CI 0.31-2.03, $p=0.63$ ) and NRSs (RR $0.82,95 \%$ CI $0.57-1.17, p=0.28)$; meanwhile, there was a statistically significant difference in NRSs (RR 0.74, 95\% CI $0.61-0.91, p=0.003$ ), but not in RCTs (RR 1.17, 95\% CI $0.50-2.74, p=0.72$ ) in open pelvic surgery (Fig. 2C). Heterogeneities in NRSs were observed in the subgroup analyses of both laparoscopic and open surgery according to the Cochran's $\mathrm{Q}$ test $(p<0.001$ and $p<0.001$, respectively) and $I^{2}$ test (70\% and 70\%, respectively). 


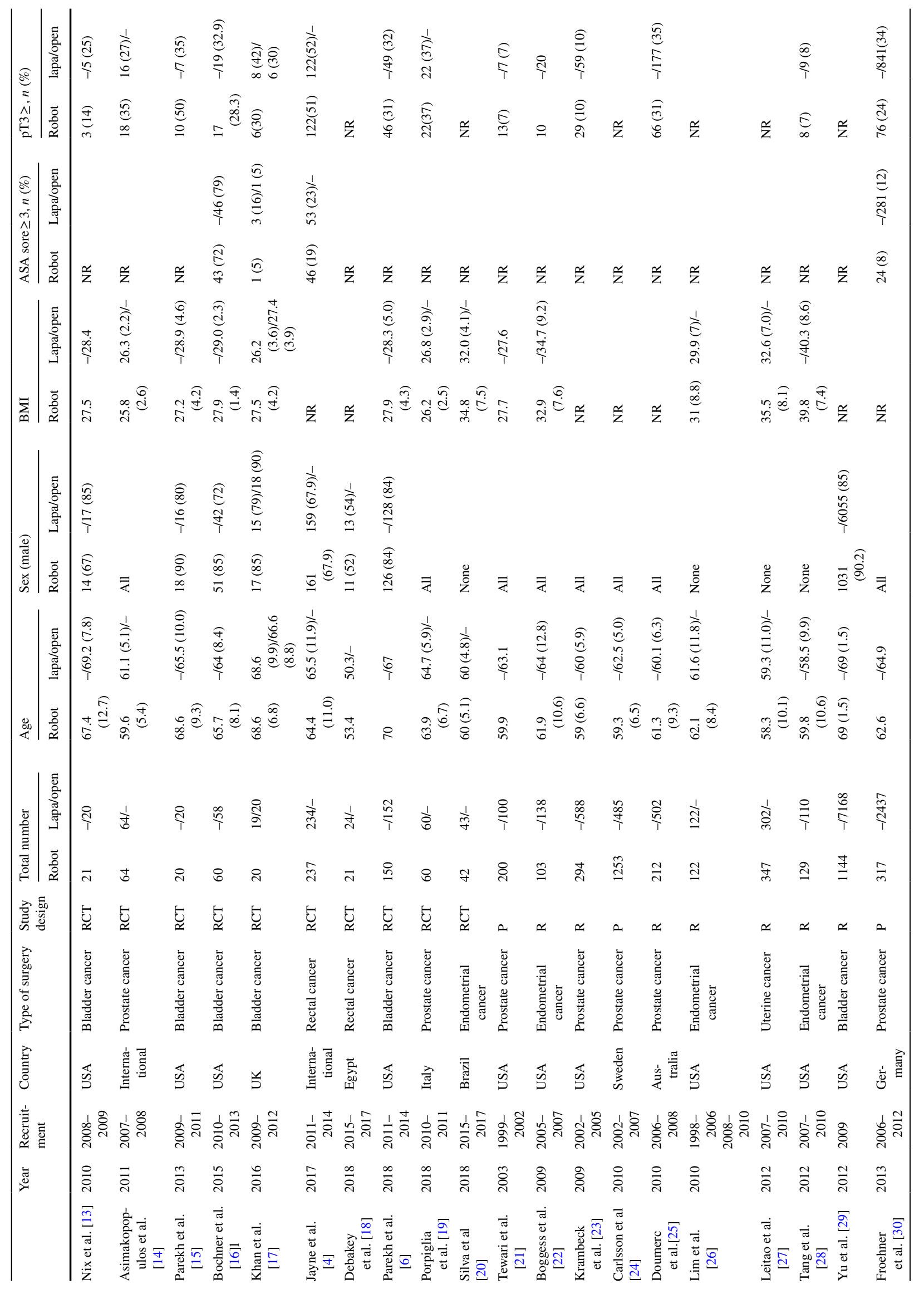




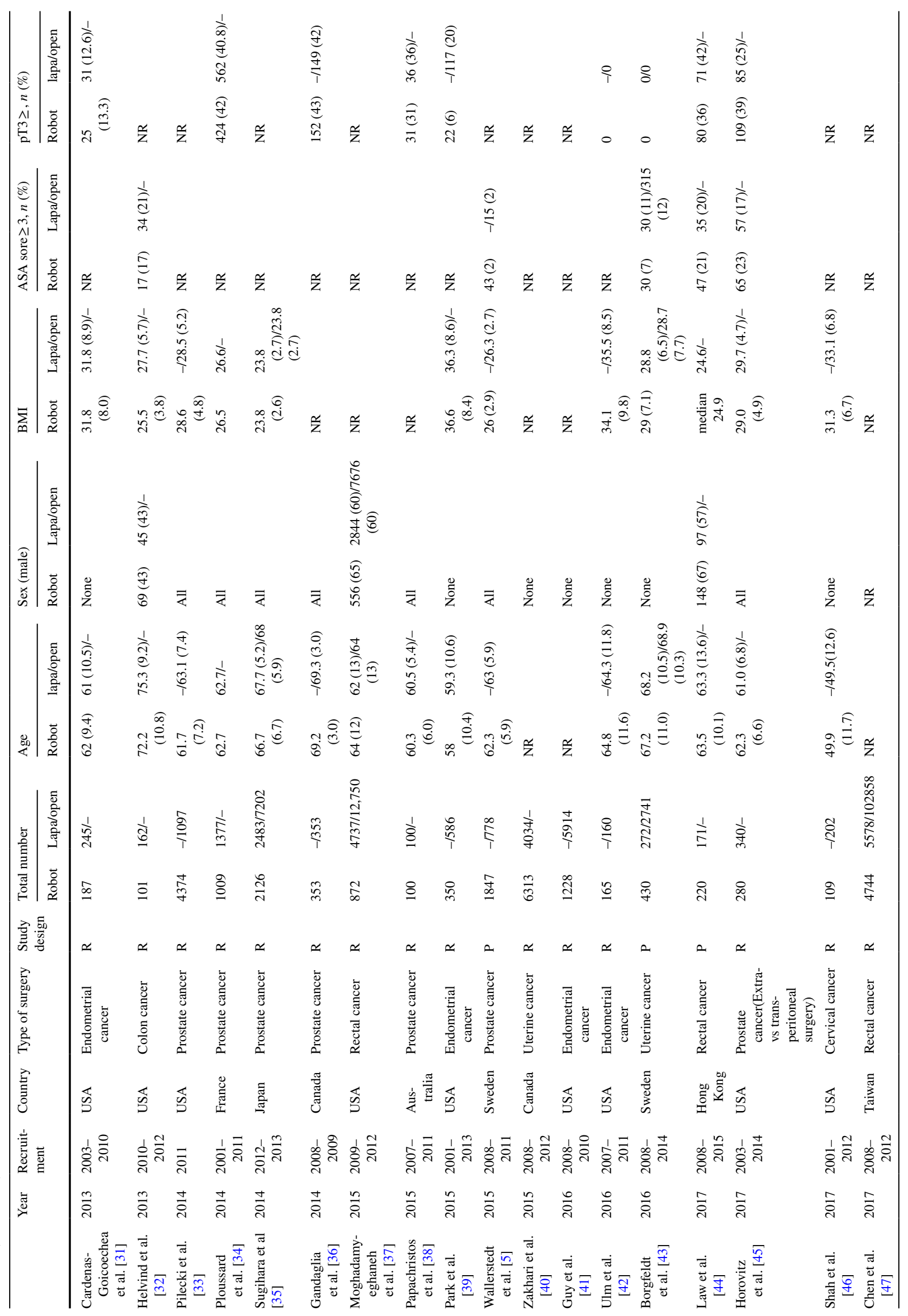




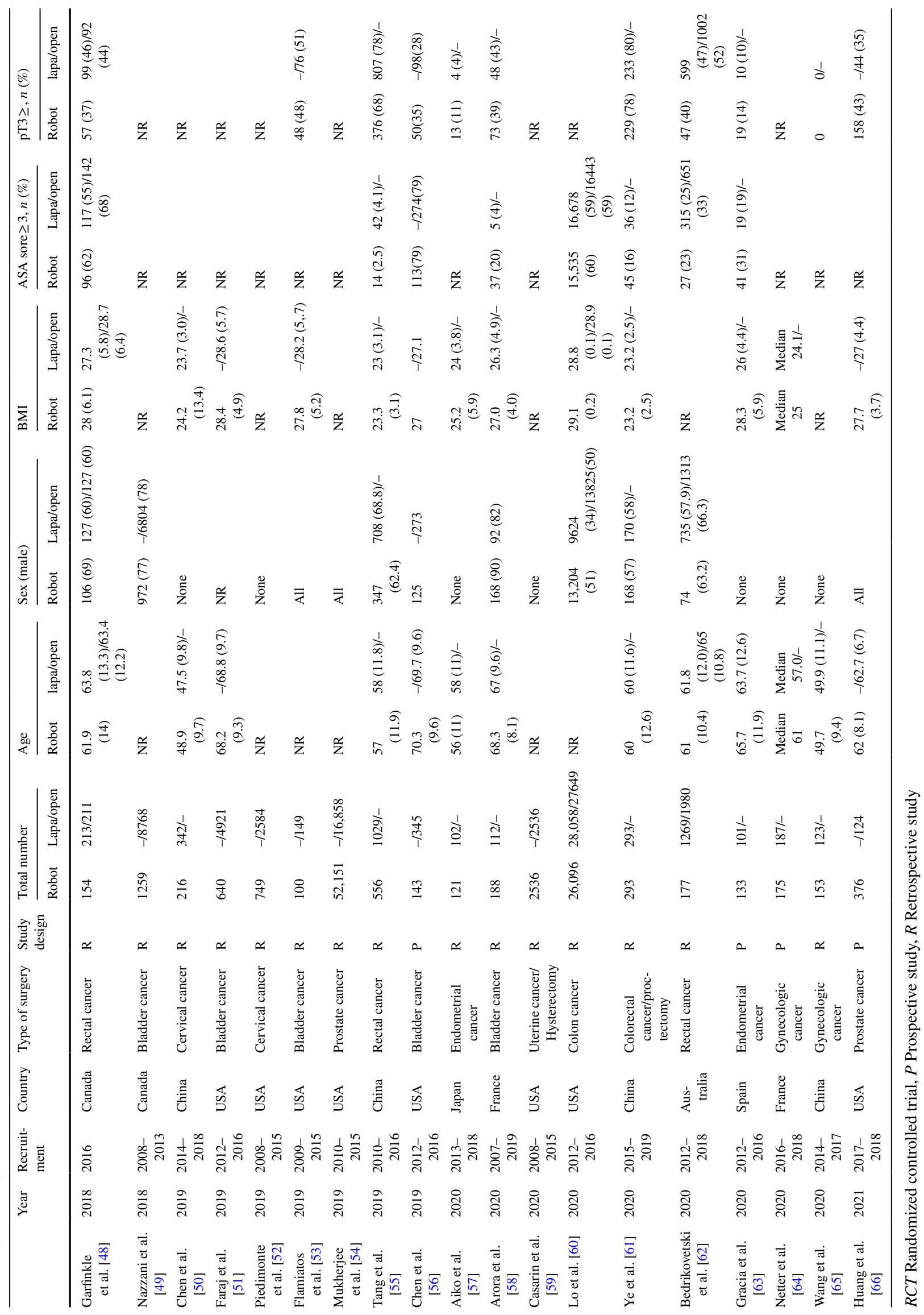


A

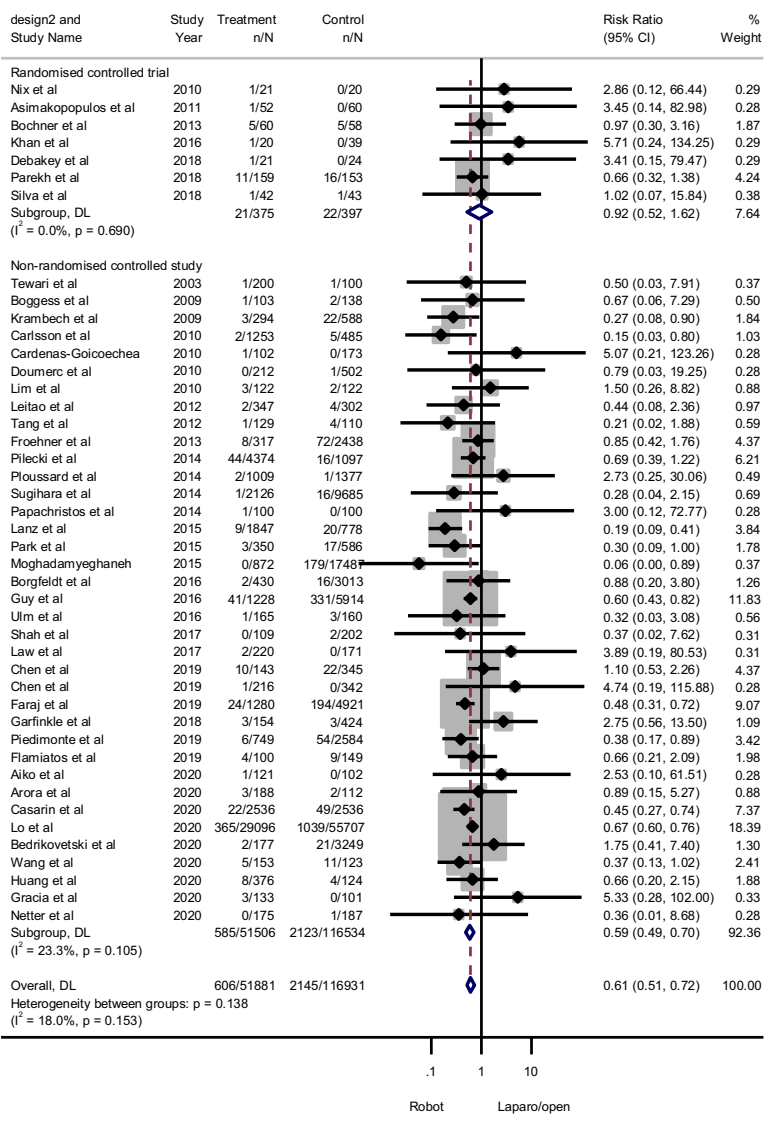

C

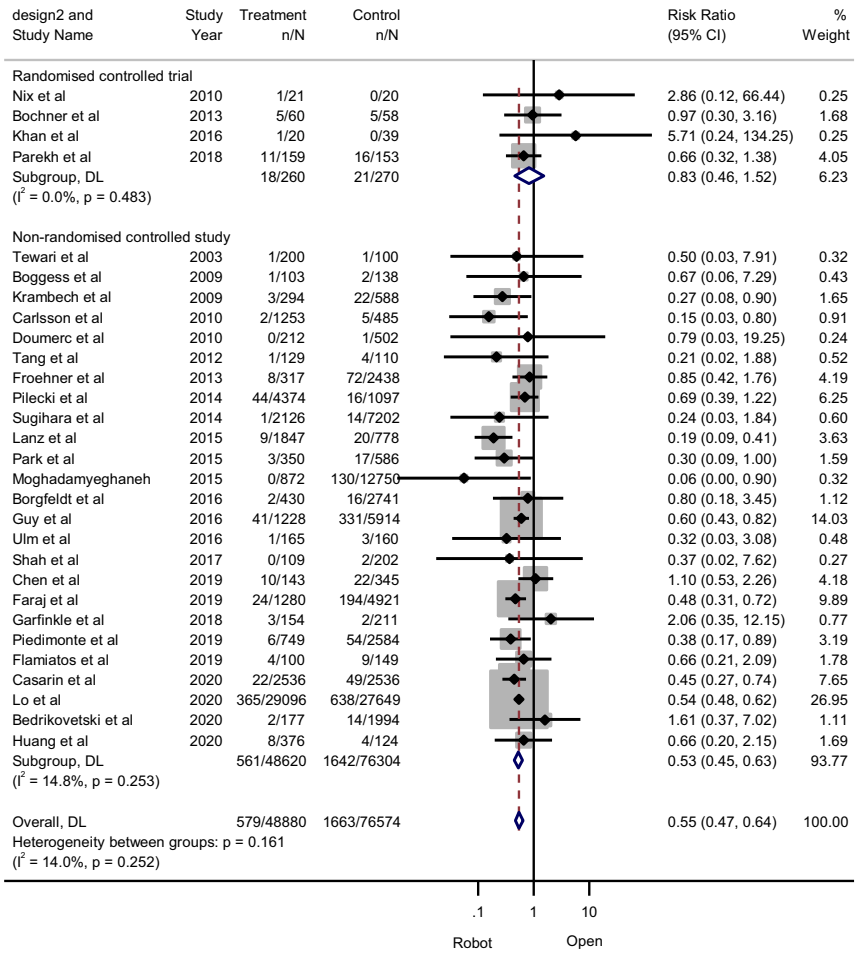

NOTE: Weights and between-subgroup heterogeneity test are from random-effects model; continuity correction applied to studies with zero cells

B

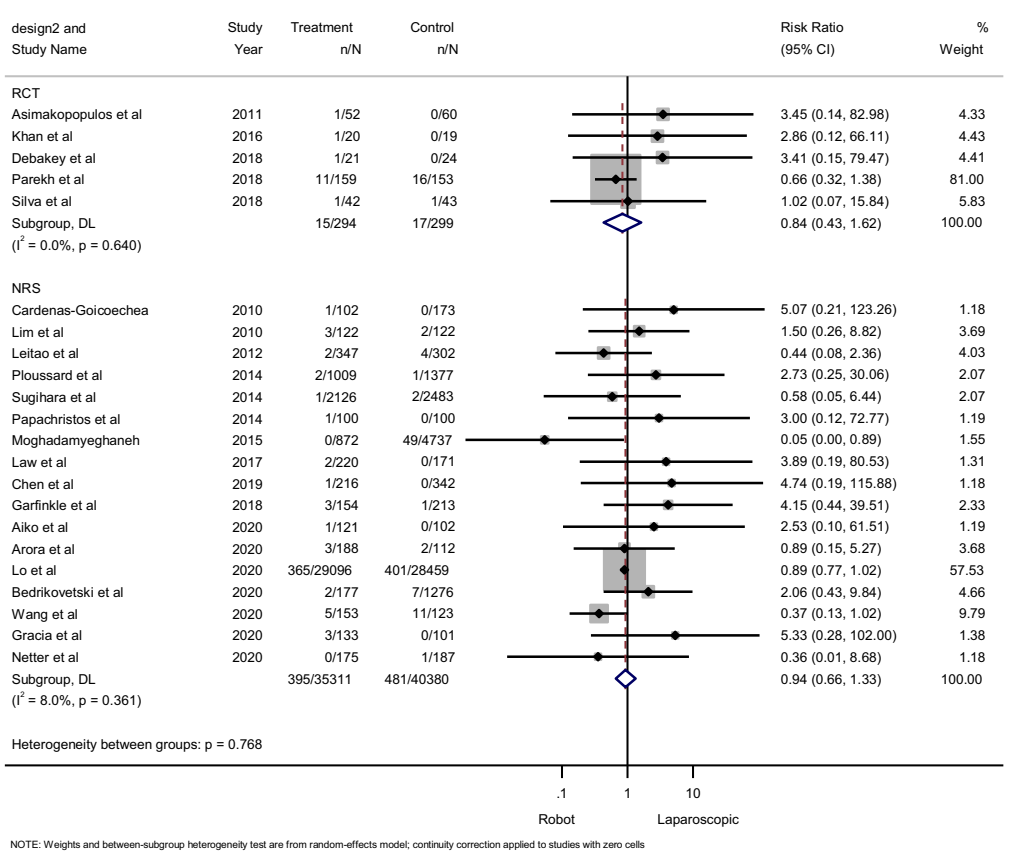

Fig. 1 Forest plots for the incidence of venous thromboembolism showing the overall association of robotic surgery (with steep Trendelenburg position) with laparoscopic and open pelvic surgery (A), subgroup analyses based on laparoscopic pelvic surgery (B), and subgroup analyses based on open pelvic surgery $(\mathbf{C})$ in both randomized controlled studies and non-randomized controlled studies 
A

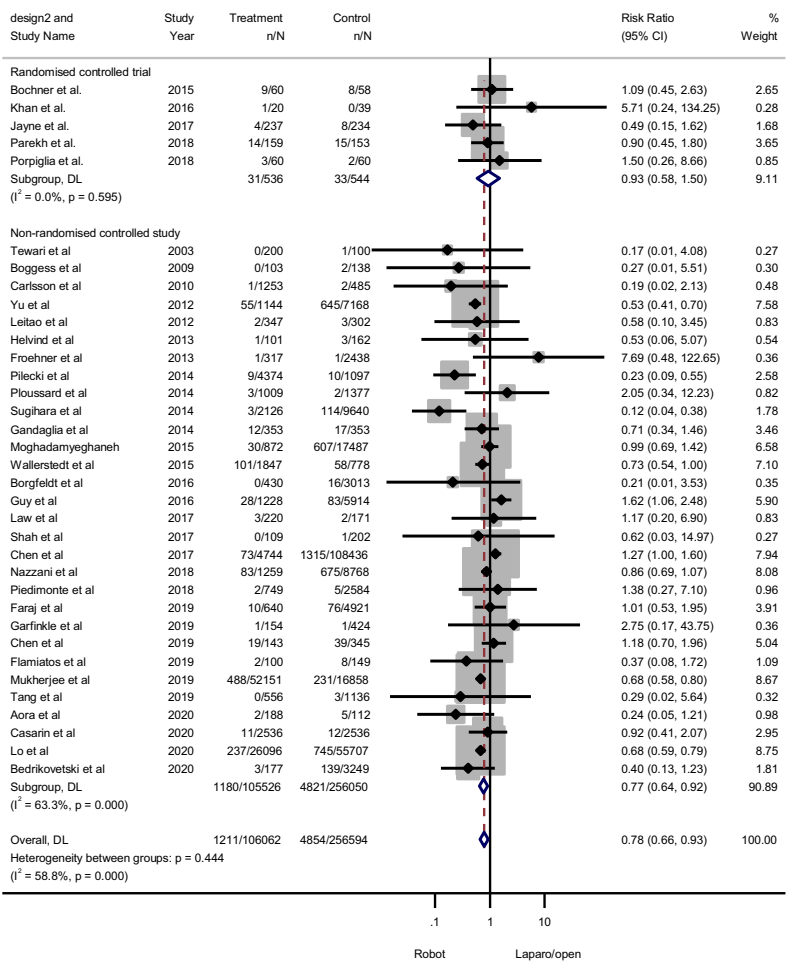

C

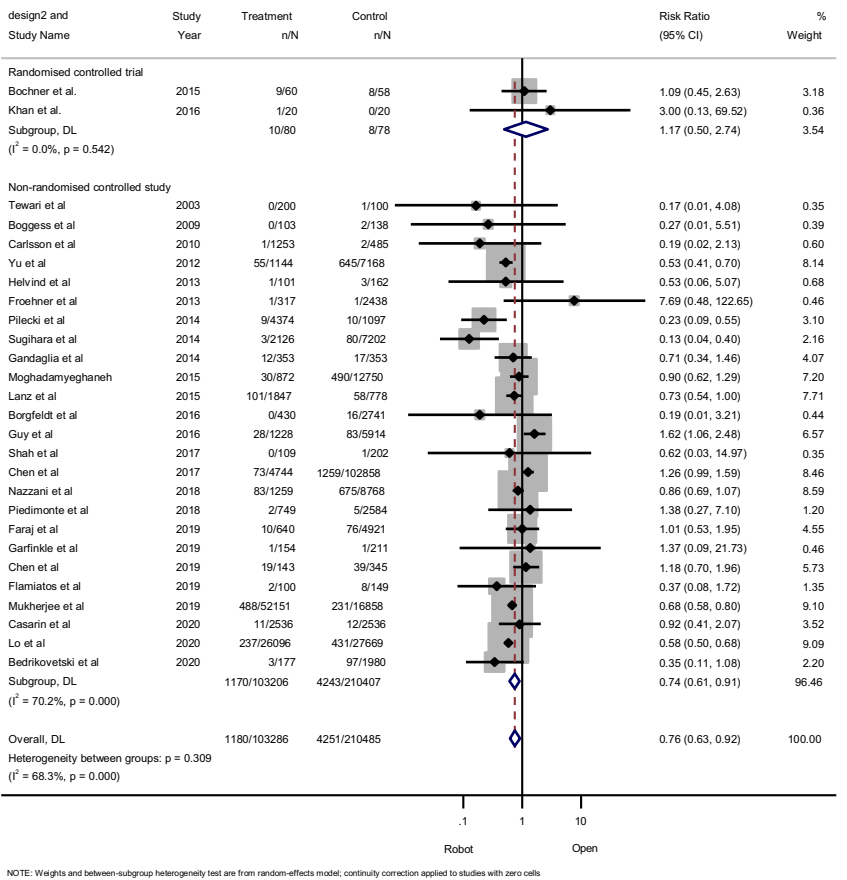

B

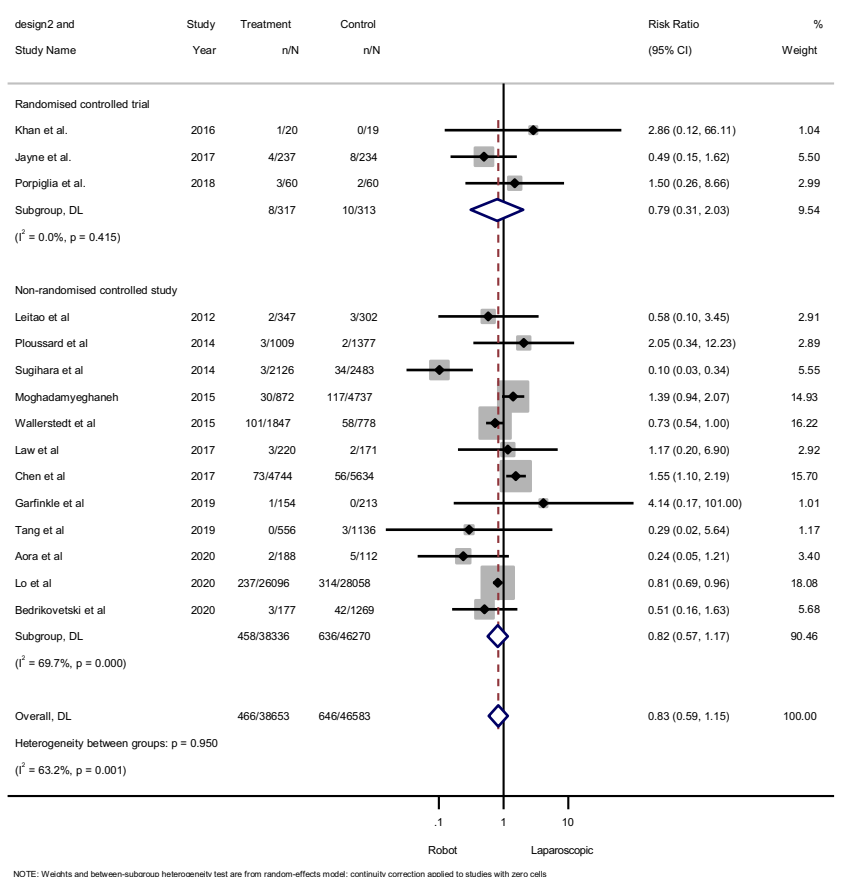

Fig. 2 Forest plots for the incidence of cardiac complications showing the overall association of robotic surgery (with steep Trendelenburg position) with laparoscopic and open pelvic surgery (A), subgroup analyses based on laparoscopic pelvic surgery (B), and subgroup analyses based on open pelvic surgery $(\mathbf{C})$ in both randomized controlled studies and non-randomized controlled studies 


\section{Cerebrovascular complications and steep Trendelenburg position}

A total of 2 RCTs comprising 511 patients and 11 NRSs with 96,585 patients provided data on cardiac complications. Forest plots (Fig. 3) revealed no significant difference in either RCTs (RR 1.01; 95\% CI 0.11-9.51; $p=0.99$ ) or NRSs (RR 0.97; 95\%CI 0.74-1.28; $p=0.83$ ). Based on the Cochran's $Q$ and $I^{2}$ tests, there was no significant heterogeneity in RCTs $\left(p=0.33, I^{2} 0 \%\right)$, while significant heterogeneity was observed in NRSs $\left(p=0.89, I^{2} 0 \%\right)$.

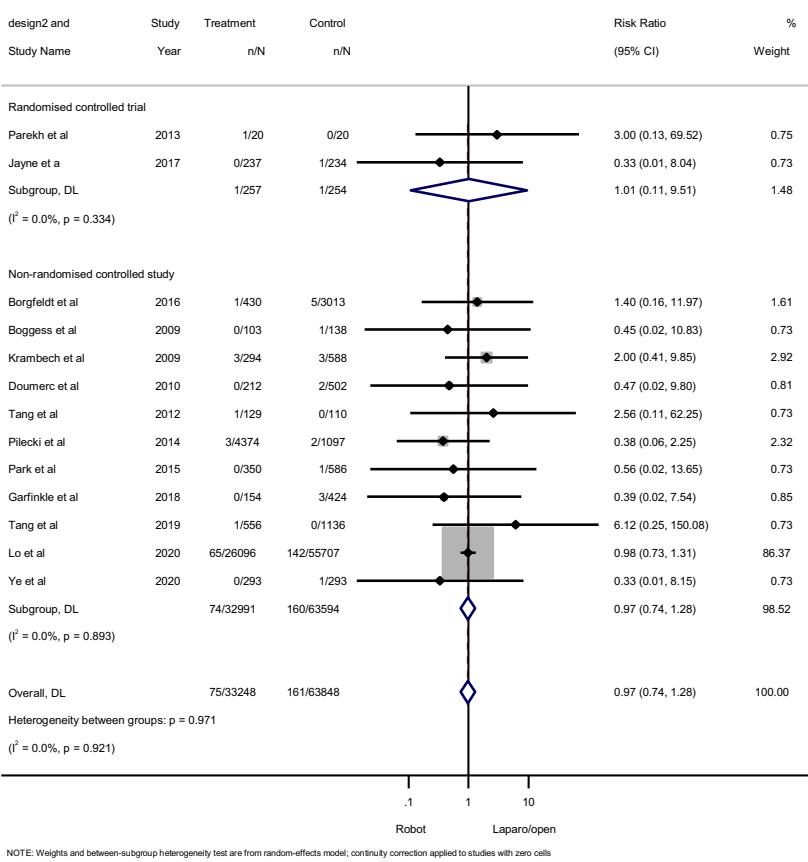

Fig. 3 Forest plots for the incidence of cerebrovascular complications showing the overall association of robotic surgery (with steep Trendelenburg position) with laparoscopic and open pelvic surgery in both randomized controlled studies and non-randomized controlled studies

\section{Heterogeneity exploration}

To explore clinically considerable heterogeneity due to the multifactorial etiology of VTE, we performed a metaregression analysis (Table 2). Among the previously identified potential variables, none of the risk factors exhibited heterogeneity.

\section{Discussion}

In this systematic review and meta-analysis, we investigated the postoperative adverse effects of steep Trendelenburg position of RAPS compared to laparoscopic and open pelvic surgeries. Although the steep Trendelenburg position was associated with a significant risk reduction in the rate of VTE and cardiac complications in NRSs, no difference was found in RCTs between the types of surgical procedures. Additionally, there was no relationship between the steep Trendelenburg position and the risk of cerebrovascular complications.

VTE is a multifactorial disease responsible for significant morbidity and mortality in the postoperative period; patients who experienced VTE after surgery have a 5.3-fold increase in the risk of mortality relative to those who did not [67]. Of the possible mechanisms, venous stasis is one of the key drivers in the development of VTE. The steep Trendelenburg position, described as head tilting of 25-45 degrees downward with leg elevated, facilitates venous return from the lower limbs and decreases blood stasis, which may result in a lower risk of developing intravascular thrombosis [68]. However, there was no significant difference in RCTs despite the presence of statistical significance in NRSs, suggesting that the presence of a steep Trendelenburg position has little to no detrimental effects on postoperative prevalence of VTE; if there is an effect then it is likely to be negligible compared to other risk factors. This is supported by the
Table 2 Results of metaregression analyses for the incidence of VTE

\begin{tabular}{llccl}
\hline Variable & No. of studies & Regression coefficient & $95 \%$ CI & $p$ value \\
\hline Cancer type & 44 & -0.07303 & $-0.1515-0.005459$ & 0.07 \\
Age & 35 & 0.2977 & $-0.2790-0.8745$ & 0.30 \\
BMI & 25 & -0.3630 & $-0.1382-0.6557$ & 0.47 \\
ASA & 12 & 0.7075 & $-0.3673-1.7822$ & 0.17 \\
Operative time & 28 & 0.001992 & $-0.009763-0.004961$ & 0.18 \\
Estimate blood loss & 23 & -0.0000864 & $-0.001571-0.001399$ & 0.91 \\
Advanced malignancy & 27 & 0.5684 & $-0.002252-1.1391$ & 0.051 \\
LN dissection & 22 & 0.3981 & $-0.1590-0.9551$ & 0.15 \\
LN yields & 16 & 0.01573 & $-0.02128-0.05274$ & 0.38 \\
LOS & 25 & 0.01064 & $-0.007443-0.02872$ & 0.24 \\
\hline
\end{tabular}

$B M I$ body mass index, ASA the American Society of Anesthesiology, $L N$ lymph node, LOS length of stay, $C I$ confidence interval 
subgroup analyses that revealed no significant difference between cases with vs those without the steep Trendelenburg position when RAPS was compared to laparoscopic pelvic surgery. There was, however, a significant difference in favor of RAPS compared to open pelvic surgery which is more likely to be associated with VTE risk factors, confounding the real impact of the Trendelenburg position. To date, several risk factors have been shown to be associated with the development of VTE. For example, Trinh et al., who analyzed 2,508,916 patients undergoing eight major surgical oncologic procedures, reported that older age, female sex, severe comorbidity, black race, and insurance status were associated with an increased risk of VTE [67]. Additionally, prolonged operative time, $\mathrm{LN}$ dissection, increased BMI, transfusion, and advanced malignancy have been found to be associated with an increased risk of VTE $[69,70]$. We assume that these semi-established risk factors affected our analyses, thereby confounding estimates of the VTE risk.

To overcome these inherent heterogeneities caused by confounders, we performed a meta-regression analysis to explore the potential explanations of clinically considerable heterogeneity in VTE driven by various risk factors. The meta-regression, however, confirmed that none of the risk factors were associated with the presence of heterogeneities. Our selection criteria (only comparative studies with $\geq 100$ patients per arm were included) may have led to the low heterogeneity in the VTE rate in both RCTs and NRSs.

The steep Trendelenburg position also induces several hemodynamic changes affecting the cardiovascular system. The head-down tilt plus leg raising leads to an increase in central venous pressure ranging from 80 to $305 \%$ [71], which increases cardiac preload. Cardiac afterload measured by the systemic vascular resistant index increases at the time of $\mathrm{CO}_{2}$ insufflation, followed by a decrease during the steep Trendelenburg position [9]. The intraoperative values of the cardiac output and contractility resulting from these changes remain controversial, varying from no change to a significant increase $[72,73]$. Rosendal et al. suggested that they are likely to pose a potential risk for higher cardiac oxygen consumption resulting in adverse cardiac events [71]. Despite these concerns, there was no difference between two types of surgical procedures in RCTs and subgroup analyses based on laparoscopic surgery, suggesting that the steep Trendelenburg position provides little to no impact on postoperative cardiac complications. Although a considerable relative risk reduction was observed in NRSs of cardiac complications as well as VTE (23\% and 39\% risk reduction, respectively), interpretations should be done with caution due to the influences of other uncontrolled confounding factors.

We also evaluated the association between the steep Trendelenburg position and cerebrovascular complications. This positioning, combined with pneumoperitoneum, has been shown to increase intracranial pressure, thereby reducing cerebral perfusion pressure (CPP) resulting in cerebral ischemia [74]. Our findings, however, showed that the steep Trendelenburg position has only negligible impact on the likelihood of postoperative cerebrovascular complications. One potential reason for this could be a compensation through a concomitant increase in mean arterial pressure for any increase of intracranial pressure, thereby maintaining CPP and cerebral oxygen saturation $[10,75,76]$.

Our meta-analysis has several limitations. First, this study includes considerable heterogeneity primarily due to the included different types of surgeries. We attempted to explain the clinically considerable heterogeneity in VTE risk by assessing the association between VTE risk and other risk factors. Although we performed metaregression and subgroup analyses, we could not explore within-study heterogeneity, which is a limitation inherent to meta-regression analysis. The unaccounted variable use of VTE prophylaxis may affect the prevalence of thromboembolism. However, included studies made little mention of measures for VTE prevention, which could not be analyzed using meta-regression. Additionally, the duration, inclination angle and practical techniques of steep Trendelenburg varied across studies, centers, surgeons. Indeed, Souki et al. described that only $2.1 \%$ of assessed institutions had a policy on the safe limits of positioning during the steep Trendelenburg position [77]. In general, the Trendelenburg angle in laparoscopic pelvic surgery may not be steep, but the variable angles of this positioning are required depending on the type of surgery, which could affect the findings of our study. Furthermore, due to the lack of standardized follow-up management, the introduction of early ambulation as well as perioperative treatment strategies including radiotherapy and chemotherapy could not be accounted for.

We found no detrimental effects related to steep Trendelenburg on postoperative complications. In addition, RAPS was associated with a significantly lower risk of VTE and cardiac complications compared to open pelvic surgery. There are concerns regarding the generalizability of these data and a need for well-designed prospective studies with long follow-up. Hypotheses such as the one suggesting that prolonged Trendelenburg position may cause postoperative cognitive decline need to be adequately assessed [78]. The European Association of Urology Robotic Urology Section Scientific Working Group recommends, indeed, prolonged postoperative use (four weeks) of low molecular weight heparin with $100 \%$ of agreement for patients performing robot-assisted radical cystectomy [79]. Rigorous methodology, scientifical and critical verification of effectiveness of the robotic platform should be continued. 


\section{Conclusion}

We found that the steep Trendelenburg position has negligible impacts on postoperative thromboembolic, cardiac, and cerebrovascular complications. However, appropriate preventive measures against these complications should be implemented. The individual risk for each patient according to his general health, tumor characteristics, and peri- and intraoperative history should guide preventative measures, especially when RAPS is performed.

Supplementary Information The online version contains supplementary material available at https://doi.org/10.1007/s11701-021-01361-x.

Acknowledgements Ekaterina Laukhtina is supported by the EUSP Scholarship of the European Association of Urology (EAU). Nico C. Grossmann is supported by the Zurich Cancer League.

Author contribution Conceptualization: SK, KM; methodology: KM, BP; formal analysis and investigation: MA, TY, HM, FQ, RSM, EL, NCG, PR; data management: AA, FK; writing-original draft preparation: SK; writing — review and editing: YN, SFS; supervision: PIK, SFS.

Funding Open access funding provided by Medical University of Vienna. This research did not receive any specific grant from funding agencies in the public, commercial, or not-for-profit sectors.

\section{Declarations}

Conflict of interest All authors state that they have no conflicts of interest that might bias this work.

Open Access This article is licensed under a Creative Commons Attribution 4.0 International License, which permits use, sharing, adaptation, distribution and reproduction in any medium or format, as long as you give appropriate credit to the original author(s) and the source, provide a link to the Creative Commons licence, and indicate if changes were made. The images or other third party material in this article are included in the article's Creative Commons licence, unless indicated otherwise in a credit line to the material. If material is not included in the article's Creative Commons licence and your intended use is not permitted by statutory regulation or exceeds the permitted use, you will need to obtain permission directly from the copyright holder. To view a copy of this licence, visit http://creativecommons.org/licenses/by/4.0/.

\section{References}

1. Peters BS, Armijo PR, Krause C, Choudhury SA, Oleynikov D (2018) Review of emerging surgical robotic technology. Surg Endosc 32(4):1636-1655. https://doi.org/10.1007/ s00464-018-6079-2

2. Wright JD (2017) Robotic-assisted surgery: balancing evidence and Implementation. JAMA 318(16):1545-1547. https://doi. org/10.1001/jama.2017.13696

3. Sheetz KH, Claflin J, Dimick JB (2020) Trends in the adoption of robotic surgery for common surgical procedures. JAMA Netw
Open 3(1):e1918911. https://doi.org/10.1001/jamanetworkopen. 2019.18911

4. Jayne D, Pigazzi A, Marshall H, Croft J, Corrigan N, Copeland J, Quirke P, West N, Rautio T, Thomassen N, Tilney H, Gudgeon M, Bianchi PP, Edlin R, Hulme C, Brown J (2017) Effect of robotic-assisted vs conventional laparoscopic surgery on risk of conversion to open laparotomy among patients undergoing resection for rectal cancer: the ROLARR randomized clinical trial. JAMA 318(16):1569-1580. https://doi.org/10.1001/jama. 2017.7219

5. Wallerstedt A, Tyritzis SI, Thorsteinsdottir T, Carlsson S, Stranne J, Gustafsson O, Hugosson J, Bjartell A, Wilderäng U, Wiklund NP, Steineck G, Haglind E (2015) Short-term results after robot-assisted laparoscopic radical prostatectomy compared to open radical prostatectomy. Eur Urol 67(4):660-670. https://doi.org/10.1016/j.eururo.2014.09.036

6. Parekh DJ, Reis IM, Castle EP, Gonzalgo ML, Woods ME, Svatek RS, Weizer AZ, Konety BR, Tollefson M, Krupski TL, Smith ND, Shabsigh A, Barocas DA, Quek ML, Dash A, Kibel AS, Shemanski L, Pruthi RS, Montgomery JS, Weight CJ, Sharp DS, Chang SS, Cookson MS, Gupta GN, Gorbonos A, Uchio EM, Skinner E, Venkatramani V, Soodana-Prakash N, Kendrick K, Smith JA Jr, Thompson IM (2018) Robot-assisted radical cystectomy versus open radical cystectomy in patients with bladder cancer (RAZOR): an open-label, randomised, phase 3, non-inferiority trial. Lancet 391(10139):2525-2536. https://doi.org/10.1016/ s0140-6736(18)30996-6

7. Yu J, Park JY, Lee Y, Hwang JH, Kim YK (2021) Sugammadex versus neostigmine on postoperative pulmonary complications after robot-assisted laparoscopic prostatectomy: a propensity score-matched analysis. J Anesth 35(2):262-269. https://doi.org/ 10.1007/s00540-021-02910-2

8. Kilic OF, Börgers A, Köhne W, Musch M, Kröpfl D, Groeben H (2015) Effects of steep Trendelenburg position for roboticassisted prostatectomies on intra- and extrathoracic airways in patients with or without chronic obstructive pulmonary disease. Br J Anaesth 114(1):70-76. https://doi.org/10.1093/bja/aeu322

9. Pawlik MT, Prasser C, Zeman F, Harth M, Burger M, Denzinger S, Blecha S (2020) Pronounced haemodynamic changes during and after robotic-assisted laparoscopic prostatectomy: a prospective observational study. BMJ Open 10(10):e038045. https://doi.org/ 10.1136/bmjopen-2020-038045

10. Whiteley JR, Taylor J, Henry M, Epperson TI, Hand WR (2015) Detection of elevated intracranial pressure in robot-assisted laparoscopic radical prostatectomy using ultrasonography of optic nerve sheath diameter. J Neurosurg Anesthesiol 27(2):155-159. https://doi.org/10.1097/ana.0000000000000106

11. Hutton B, Salanti G, Caldwell DM, Chaimani A, Schmid CH, Cameron C, Ioannidis JP, Straus S, Thorlund K, Jansen JP, Mulrow C, Catalá-López F, Gøtzsche PC, Dickersin K, Boutron I, Altman DG, Moher D (2015) The PRISMA extension statement for reporting of systematic reviews incorporating network meta-analyses of health care interventions: checklist and explanations. Ann Intern Med 162(11):777-784. https://doi.org/10.7326/m14-2385

12. Wan X, Wang W, Liu J, Tong T (2014) Estimating the sample mean and standard deviation from the sample size, median, range and/or interquartile range. BMC Med Res Methodol 14:135. https://doi.org/10.1186/1471-2288-14-135

13. Nix J, Smith A, Kurpad R, Nielsen ME, Wallen EM, Pruthi RS (2010) Prospective randomized controlled trial of robotic versus open radical cystectomy for bladder cancer: perioperative and pathologic results. Eur Urol 57(2):196-201. https://doi.org/10. 1016/j.eururo.2009.10.024

14. Asimakopoulos AD, Fraga CTP, Annino F, Pasqualetti P, Calado AA, Mugnier C (2011) Randomized comparison between laparoscopic and robot-assisted nerve-sparing radical prostatectomy. 
J Sex Med 8(5):1503-1512. https://doi.org/10.1111/j.1743-6109. 2011.02215.x

15. Bochner BH, Dalbagni G, Sjoberg DD, Silberstein J, Keren Paz GE, Donat SM, Coleman JA, Mathew S, Vickers A, Schnorr GC, Feuerstein MA, Rapkin B, Parra RO, Herr HW, Laudone VP (2015) Comparing open radical cystectomy and robot-assisted laparoscopic radical cystectomy: a randomized clinical trial. Eur Urol 67(6):1042-1050. https://doi.org/10.1016/j.eururo.2014.11. 043

16. Parekh DJ, Messer J, Fitzgerald J, Ercole B, Svatek R (2013) Perioperative outcomes and oncologic efficacy from a pilot prospective randomized clinical trial of open versus robotic assisted radical cystectomy. J Urol 189(2):474-479. https://doi.org/10. 1016/j.juro.2012.09.077

17. Khan MS, Gan C, Ahmed K, Ismail AF, Watkins J, Summers JA, Peacock JL, Rimington P, Dasgupta P (2016) A single-centre early phase randomised controlled three-arm trial of open, robotic, and laparoscopic radical cystectomy (CORAL). Eur Urol 69(4):613621. https://doi.org/10.1016/j.eururo.2015.07.038

18. Debakey Y, Zaghloul A, Farag A, Mahmoud A, Elattar I (2018) Robotic-assisted versus conventional laparoscopic approach for rectal cancer surgery, first egyptian academic center experience. RCT Minim Invasive Surg. https://doi.org/10.1155/2018/5836562

19. Porpiglia F, Fiori C, Bertolo R, Manfredi M, Mele F, Checcucci E, De Luca S, Passera R, Scarpa RM (2018) Five-year outcomes for a prospective randomised controlled trial comparing laparoscopic and robot-assisted radical prostatectomy. Eur Urol Focus 4(1):80-86. https://doi.org/10.1016/j.euf.2016.11.007

20. Silva AE, de Carvalho JPM, Anton C, Fernandes RP, Baracat EC, Carvalho JP (2018) Introduction of robotic surgery for endometrial cancer into a Brazilian cancer service: a randomized trial evaluating perioperative clinical outcomes and costs 6061/clinics/2017/e522s. Clinics. https://doi.org/10.6061/clinics/2017/ e522s

21. Tewari A, Srivasatava A, Menon M (2003) A prospective comparison of radical retropubic and robot-assisted prostatectomy: experience in one institution. BJU Int 92(3):205-210. https://doi. org/10.1046/j.1464-410X.2003.04311.x

22. Boggess JF, Gehrig PA, Cantrell L, Shafer A, Ridgway M, Skinner EN, Fowler WC (2008) A comparative study of 3 surgical methods for hysterectomy with staging for endometrial cancer: robotic assistance, laparoscopy, laparotomy. Am J Obstet Gynecol 199(4):360.e361-369. https://doi.org/10.1016/j.ajog.2008.08.012

23. Krambeck AE, DiMarco DS, Rangel LJ, Bergstralh EJ, Myers RP, Blute ML, Gettman MT (2009) Radical prostatectomy for prostatic adenocarcinoma: a matched comparison of open retropubic and robot-assisted techniques. BJU Int 103(4):448-453. https:// doi.org/10.1111/j.1464-410X.2008.08012.x

24. Carlsson S, Nilsson AE, Schumacher MC, Jonsson MN, Volz DS, Steineck G, Wiklund PN (2010) Surgery-related complications in 1253 robot-assisted and 485 open retropubic radical prostatectomies at the karolinska university hospital. Sweden Urology 75(5):1092-1097. https://doi.org/10.1016/j.urology.2009.09.075

25. Doumerc N, Yuen C, Savdie R, Rahman MB, Rasiah KK, Pe Benito R, Delprado W, Matthews J, Haynes AM, Stricker PD (2010) Should experienced open prostatic surgeons convert to robotic surgery? The real learning curve for one surgeon over 3 years. BJU Int 106(3):378-384. https://doi.org/10.1111/j.1464-410X. 2009.09158.x

26. Lim PC, Kang E, Park DH (2011) A comparative detail analysis of the learning curve and surgical outcome for robotic hysterectomy with lymphadenectomy versus laparoscopic hysterectomy with lymphadenectomy in treatment of endometrial cancer: a case-matched controlled study of the first one hundred twenty two patients. Gynecol Oncol 120(3):413-418. https://doi.org/10. 1016/j.ygyno.2010.11.034
27. Leitao MM, Briscoe G, Santos K, Winder A, Jewell EL, Hoskins WJ, Chi DS, Abu-Rustum NR, Sonoda Y, Brown CL, Levine DA, Barakat RR, Gardner GJ (2012) Introduction of a computer-based surgical platform in the surgical care of patients with newly diagnosed uterine cancer: outcomes and impact on approach. Gynecol Oncol 125(2):394-399. https://doi.org/10.1016/j.ygyno.2012.01. 046

28. Tang KY, Gardiner SK, Gould C, Osmundsen B, Collins M, Winter WE (2012) Robotic surgical staging for obese patients with endometrial cancer. Am J Obstet Gynecol. https://doi.org/ 10.1016/j.ajog.2012.01.002

29. Yu HY, Hevelone ND, Lipsitz SR, Kowalczyk KJ, Nguyen PL, Choueiri TK, Kibel AS, Hu JC (2012) Comparative analysis of outcomes and costs following open radical cystectomy versus robot-assisted laparoscopic radical cystectomy: results from the us nationwide inpatient sample. Eur Urol 61(6):1239-1244. https:// doi.org/10.1016/j.eururo.2012.03.032

30. Froehner M, Novotny V, Koch R, Leike S, Twelker L, Wirth MP (2013) Perioperative complications after radical prostatectomy: open versus robot-assisted laparoscopic approach. Urol Int 90(3):312-315. https://doi.org/10.1159/000345323

31. Cardenas-Goicoechea J, Soto E, Chuang L, Gretz H, Randall TC (2013) Integration of robotics into two established programs of minimally invasive surgery for endometrial cancer appears to decrease surgical complications. J Gynecol Oncol 24(1):21-28. https://doi.org/10.3802/jgo.2013.24.1.21

32. Helvind NM, Eriksen JR, Mogensen A, Tas B, Olsen J, Bundgaard M, Jakobsen HL, Gogenur I (2013) No differences in short-term morbidity and mortality after robot-assisted laparoscopic versus laparoscopic resection for colonic cancer: a case-control study of 263 patients. Surg Endosc Other Interv Tech 27(7):2575-2580. https://doi.org/10.1007/s00464-013-2792-Z

33. Pilecki MA, McGuire BB, Jain U, Kim JY, Nadler RB (2014) National multi-institutional comparison of 30-day postoperative complication and readmission rates between open retropubic radical prostatectomy and robot-assisted laparoscopic prostatectomy using NSQIP. J Endourol 28(4):430-436. https://doi.org/10.1089/ end.2013.0656

34. Ploussard G, de la Taille A, Moulin M, Vordos D, Hoznek A, Abbou CC, Salomon L (2014) Comparisons of the perioperative, functional, and oncologic outcomes after robot-assisted versus pure extraperitoneal laparoscopic radical prostatectomy. Eur Urol 65(3):610-619. https://doi.org/10.1016/j.eururo.2012.11.049

35. Sugihara T, Yasunaga $H$, Horiguchi $H$, Matsui H, Fujimura T, Nishimatsu H, Fukuhara H, Kume H, Yu CH, Kattan MW, Fushimi K, Homma Y (2014) Robot-assisted versus other types of radical prostatectomy: population-based safety and cost comparison in Japan, 2012-2013. Cancer Sci 105(11):1421-1426. https://doi. org/10.1111/cas. 12523

36. Gandaglia G, Sammon JD, Chang SL, Choueiri TK, Hu JC, Karakiewicz PI, Kibel AS, Kim SP, Konijeti R, Montorsi F, Nguyen PL, Sukumar S, Menon M, Sun M, Trinh QD (2014) Comparative effectiveness of robot-assisted and open radical prostatectomy in the postdissemination era. J Clin Oncol 32(14):1419. https://doi.org/10.1200/jco.2013.53.5096

37. Moghadamyeghaneh Z, Phelan M, Smith BR, Stamos MJ (2015) Outcomes of open, laparoscopic, and robotic abdominoperineal resections in patients with rectal cancer. Dis Colon Rectum 58(12):1123-1129. https://doi.org/10.1097/dcr.0000000000 000475

38. Papachristos A, Basto M, Te Marvelde L, Moon D (2015) Laparoscopic versus robotic-assisted radical prostatectomy: an Australian single-surgeon series. ANZ J Surg 85(3):154-158. https://doi.org/ 10.1111/ans.12602

39. Park HK, Helenowski IB, Berry E, Lurain JR, Neubauer NL (2015) A Comparison of survival and recurrence outcomes in 
patients with endometrial cancer undergoing robotic versus open surgery. J Minim Invasive Gynecol 22(6):961-967. https://doi.org/ 10.1016/j.jmig.2015.04.018

40 Zakhari A, Czuzoj-Shulman N, Spence AR, Gotlieb WH, Abenhaim HA (2015) Laparoscopic and robot-assisted hysterectomy for uterine cancer: a comparison of costs and complications. Am J Obstet Gynecol. https://doi.org/10.1016/j.ajog.2015.07.004

41. Guy MS, Sheeder J, Behbakht K, Wright JD, Guntupalli SR (2016) Comparative outcomes in older and younger women undergoing laparotomy or robotic surgical staging for endometrial cancer. Am J Obstet Gynecol 214(3):350.e351-350.e310. https://doi. org/10.1016/j.ajog.2015.09.085

42. Ulm MA, Ginn DN, ElNaggar AC, Tillmanns TD, Reed KM, Wan JY, Watson CH, Dedania SJ, Reed ME (2016) A comparison of outcomes following robotic-assisted staging and laparotomy in patients with early stage endometrioid adenocarcinoma of the uterus with uterine weight under $480 \mathrm{~g}$. Gynecol Minim Invasive Ther-Gmit 5(1):25-29. https://doi.org/10.1016/j.gmit.2015.09.002

43. Borgfeldt C, Kalapotharakos G, Asciutto KC, Lofgren M, Hogberg T (2016) A population-based registry study evaluating surgery in newly diagnosed uterine cancer. Acta Obstet Gynecol Scand 95(8):901-911. https://doi.org/10.1111/aogs.12918

44. Law WL, Foo DCC (2017) Comparison of short-term and oncologic outcomes of robotic and laparoscopic resection for mid- and distal rectal cancer. Surg Endosc 31(7):2798-2807. https://doi.org/ 10.1007/s00464-016-5289-8

45. Horovitz D, Feng CY, Messing EM, Joseph JV (2017) Extraperitoneal vs transperitoneal robot-assisted radical prostatectomy in the setting of prior abdominal or pelvic surgery. J Endourol 31(4):366-373. https://doi.org/10.1089/end.2016.0706

46. Shah CA, Beck T, Liao JB, Giannakopoulos NV, Veljovich D, Paley P (2017) Surgical and oncologic outcomes after robotic radical hysterectomy as compared to open radical hysterectomy in the treatment of early cervical cancer. J Gynecol Oncol 28(6):e82. https://doi.org/10.3802/jgo.2017.28.e82

47. Chen ST, Wu MC, Hsu TC, Yen DW, Chang CN, Hsu WT, Wang CC, Lee M, Liu SH, Lee CC (2018) Comparison of outcome and cost among open, laparoscopic, and robotic surgical treatments for rectal cancer: a propensity score matched analysis of nationwide inpatient sample data. J Surg Oncol 117(3):497-505. https://doi. org/10.1002/jso.24867

48. Garfinkle R, Abou-Khalil M, Bhatnagar S, Wong-Chong N, Azoulay L, Morin N, Vasilevsky CA, Boutros M (2019) A comparison of pathologic outcomes of open, laparoscopic, and robotic resections for rectal cancer using the ACS-NSQIP proctectomytargeted database: a propensity score analysis. J Gastrointest Surg 23(2):348-356. https://doi.org/10.1007/s11605-018-3974-8

49. Nazzani S, Mazzone E, Preisser F, Bandini M, Tian Z, Marchioni M, Ratti D, Motta G, Zorn KC, Briganti A, Shariat SF, Montanari E, Carmignani L, Karakiewicz PI (2018) Comparison of perioperative outcomes between open and robotic radical cystectomy: a population-based analysis. J Endourol 32(8):701-709. https://doi. org/10.1089/end.2018.0313

50. Chen L, Liu LP, Wen N, Qiao X, Meng YG (2019) Comparative analysis of robotic vs laparoscopic radical hysterectomy for cervical cancer. World J Clin Cases 7(20):3185-3193. https://doi.org/ 10.12998/wjcc.v7.i20.3185

51. Faraj K, Chang YHH, Neville MR, Blodgett G, Etzioni DA, Habermann EB, Andrews PE, Castle EP, Humphreys MR, Tyson MD (2019) Robotic vs. open cystectomy: how length-of-stay differences relate conditionally to age. Urol Oncol-Semin Orig Investig. https://doi.org/10.1016/j.urolonc.2019.01.028

52. Piedimonte S, Czuzoj-Shulman N, Gotlieb W, Abenhaim HA (2019) Robotic radical hysterectomy for cervical cancer: a population-based study of adoption and immediate postoperative outcomes in the United States. J Minim Invasive Gynecol 26(3):551-557. https://doi.org/10.1016/j.jmig.2018.08.012

53. Flamiatos JF, Chen YY, Lambert WE, Acevedo AM, Becker TM, Bash JC, Amling CL (2019) Open versus robot-assisted radical cystectomy: 30-day perioperative comparison and predictors for cost-to-patient, complication, and readmission. J Robot Surg 13(1):129-140. https://doi.org/10.1007/s11701-018-0832-3

54. Mukherjee K, Kamal KM (2019) Variation in prostate surgery costs and outcomes in the USA: robot-assisted versus open radical prostatectomy. J Comp Eff Res 8(3):143-155. https://doi.org/10. 2217/cer-2018-0109

55. Tang B, Li C, Liu HC, Zhang C, Luo HX, Yu PW (2019) Robotic versus laparoscopic rectal resection surgery: Short-term outcomes and complications: a retrospective comparative study. Surg OncolOxford 29:71-77. https://doi.org/10.1016/j.suronc.2019.02.004

56. Chen J, Djaladat H, Schuckman AK, Aron M, Desai M, Gill IS, Clifford TG, Ghodoussipour S, Miranda G, Cai J, Daneshmand S (2019) Surgical approach as a determinant factor of clinical outcome following radical cystectomy: Does Enhanced Recovery After Surgery (ERAS) level the playing field? Urol Oncol-Semin Orig Investig 37(10):765-773. https://doi.org/10.1016/j.urolonc. 2019.06.001

57. Aiko K, Kanno K, Yanai S, Masuda S, Yasui M, Ichikawa F, Teishikata Y, Shirane T, Yoshino Y, Sakate S, Sawada M, Shirane A, Ota Y, Andou M (2020) Short-term outcomes of robot-assisted versus conventional laparoscopic surgery for early-stage endometrial cancer: a retrospective, single-center study. J Obstet Gynaecol Res 46(7):1157-1164. https://doi.org/10.1111/jog.14293

58. Arora A, Pugliesi F, Zugail AS, Moschini M, Pazeto C, Macek P, Stabile A, Lanz C, Mombet A, Bennamoun M, Sanchez-Salas $\mathrm{R}$, Cathelineau X (2020) Comparing perioperative complications between laparoscopic and robotic radical cystectomy for bladder cancer. J Endourol 34(10):1033-1040. https://doi.org/10.1089/ end. 2020.0112

59. Casarin J, Song C, Multinu F, Cappuccio S, Liu E, Butler KA, Glaser GE, Cliby WA, Langstraat CL, Ghezzi F, Fu AZ, Mariani A (2020) Implementing robotic surgery for uterine cancer in the United States: Better outcomes without increased costs. Gynecol Oncol 156(2):451-458. https://doi.org/10.1016/j.ygyno.2019.11. 016

60. Lo BD, Leeds IL, Sundel MH, Gearhart S, Nisly GRC, Safar B, Atallah C, Fang SH (2020) Frailer patients undergoing robotic colectomies for colon cancer experience increased complication rates compared with open or laparoscopic approaches. Dis Colon Rectum 63(5):588-597. https://doi.org/10.1097/dcr.0000000000 001598

61. Ye SP, Zhu WQ, Liu DN, Lei X, Jiang QG, Hu HM, Tang B, He PH, Gao GM, Tang HC, Shi J, Li TY (2020) Robotic- vs laparoscopic-assisted proctectomy for locally advanced rectal cancer based on propensity score matching: short-term outcomes at a colorectal center in China. World J Gastrointest Oncol. https:// doi.org/10.4251/wjgo.v12.i4.424

62. Bedrikovetski S, Dudi-Venkata NN, Kroon HM, Moore JW, Hunter RA, Sammour T (2020) Outcomes of minimally invasive versus open proctectomy for rectal cancer: a propensity-matched analysis of bi-national colorectal cancer audit data. Dis Colon Rectum 63(6):778-787. https://doi.org/10.1097/dcr.0000000000 001654

63. Gracia M, Garcia-Santos J, Ramirez M, Bellon M, Herraiz MA, Coronado PJ (2020) Value of robotic surgery in endometrial cancer by body mass index. Int J Gynecol Obstet 150(3):398-405. https://doi.org/10.1002/ijgo.13258

64. Netter A, Jauffret C, Brun C, Sabiani L, Blache G, Houvenaeghel G, Lambaudie E (2020) Choosing the most appropriate minimally invasive approach to treat gynecologic cancers in the context of an enhanced recovery program: insights from a comprehensive 
cancer center. Plos One. https://doi.org/10.1371/journal.pone. 0231793

65. Wang LL, Yan PJ, Yao L, Liu R, Hou F, Chen XH, Han LL, Xu LY, Xu H, Li J, Guo TK, Yang KH, Wang HL (2020) Evaluation of intra- and post-operative outcomes to compare robot-assisted surgery and conventional laparoscopy for gynecologic oncology. Asian J Surg 43(1):347-353. https://doi.org/10.1016/j.asjsur.2019. 05.003

66. Huang MTM, Su ZT, Becker REN, Pavlovich CP, Partin AW, Allaf ME, Patel HD (2021) Complications after open and robotassisted radical prostatectomy and association with postoperative opioid use: an analysis of data from the PREVENTER trial. BJU Int. https://doi.org/10.1111/bju.15172

67. Trinh VQ, Karakiewicz PI, Sammon J, Sun M, Sukumar S, Gervais MK, Shariat SF, Tian Z, Kim SP, Kowalczyk KJ, Hu JC, Menon M, Trinh QD (2014) Venous thromboembolism after major cancer surgery: temporal trends and patterns of care. JAMA Surg 149(1):43-49. https://doi.org/10.1001/jamasurg.2013.3172

68. SooHoo GW (2013) Overview and assessment of risk factors for pulmonary embolism. Expert Rev Respir Med 7(2):171-191. https://doi.org/10.1586/ers.13.7

69. Abel EJ, Wong K, Sado M, Leverson GE, Patel SR, Downs TM, Jarrard DF (2014) Surgical operative time increases the risk of deep venous thrombosis and pulmonary embolism in robotic prostatectomy. Jsls 18(2):282-287. https://doi.org/10.4293/10868 $0813 \times 13693422518551$

70. Van Hemelrijck M, Garmo H, Holmberg L, Bill-Axelson A, Carlsson S, Akre O, Stattin P, Adolfsson J (2013) Thromboembolic events following surgery for prostate cancer. Eur Urol 63(2):354363. https://doi.org/10.1016/j.eururo.2012.09.041

71. Rosendal C, Markin S, Hien MD, Motsch J, Roggenbach J (2014) Cardiac and hemodynamic consequences during capnoperitoneum and steep Trendelenburg positioning: lessons learned from robotassisted laparoscopic prostatectomy. J Clin Anesth 26(5):383-389. https://doi.org/10.1016/j.jclinane.2014.01.014

72. Haas S, Haese A, Goetz AE, Kubitz JC (2011) Haemodynamics and cardiac function during robotic-assisted laparoscopic prostatectomy in steep Trendelenburg position. Int J Med Robot 7(4):408-413. https://doi.org/10.1002/rcs.410

73. Ono N, Nakahira J, Nakano S, Sawai T, Minami T (2017) Changes in cardiac function and hemodynamics during robot-assisted laparoscopic prostatectomy with steep head-down tilt: a prospective observational study. BMC Res Notes 10(1):341. https://doi.org/ 10.1186/s13104-017-2672-z
74. Sujata N, Tobin R, Tamhankar A, Gautam G, Yatoo AH (2019) A randomised trial to compare the increase in intracranial pressure as correlated with the optic nerve sheath diameter during propofol versus sevoflurane-maintained anesthesia in robot-assisted laparoscopic pelvic surgery. J Robot Surg 13(2):267-273. https://doi. org/10.1007/s11701-018-0849-7

75. Wiesinger C, Schoeb DS, Stockhammer M, Mirtezani E, Mitterschiffthaler L, Wagner H, Knotzer J, Pauer W (2020) Cerebral oxygenation in 45-degree trendelenburg position for robotassisted radical prostatectomy: a single-center, open, controlled pilot study. BMC Urol 20(1):198. https://doi.org/10.1186/ s12894-020-00774-4

76. Tanaka N, Yamamoto M, Abe T, Osawa T, Matsumoto R, Shinohara N, Saito H, Uchida Y, Morimoto Y (2019) Changes of cerebral blood volume during robot-assisted laparoscopic radical prostatectomy: observational prospective study using nearinfrared time-resolved spectroscopy. J Endourol 33(12):995-1001. https://doi.org/10.1089/end.2019.0217

77. Souki FG, Rodriguez-Blanco YF, Polu SR, Eber S, Candiotti KA (2018) Survey of anesthesiologists' practices related to steep Trendelenburg positioning in the USA. BMC Anesthesiol 18(1):117. https://doi.org/10.1186/s12871-018-0578-5

78. Vitish-Sharma P, Maxwell-Armstrong C, Guo B, Yick C, Acheson AG (2019) The trendelenburg position and cognitive decline: a case-control interventional study involving healthy volunteers. JMIR Perioper Med 2(1):e11219. https://doi.org/10.2196/11219

79. Collins JW, Patel H, Adding C, Annerstedt M, Dasgupta P, Khan SM, Artibani W, Gaston R, Piechaud T, Catto JW, Koupparis A, Rowe E, Perry M, Issa R, McGrath J, Kelly J, Schumacher M, Wijburg C, Canda AE, Balbay MD, Decaestecker K, Schwentner C, Stenzl A, Edeling S, Pokupić S, Stockle M, Siemer S, SanchezSalas R, Cathelineau X, Weston R, Johnson M, D’Hondt F, Mottrie A, Hosseini A, Wiklund PN (2016) Enhanced recovery after robot-assisted radical cystectomy: EAU robotic urology section scientific working group consensus view. Eur Urol 70(4):649-660. https://doi.org/10.1016/j.eururo.2016.05.020

Publisher's Note Springer Nature remains neutral with regard to jurisdictional claims in published maps and institutional affiliations.

\section{Authors and Affiliations}

\section{Satoshi Katayama ${ }^{1,2} \odot$. Keiichiro Mori ${ }^{1,3} \cdot$ Benjamin Pradere ${ }^{1} \cdot$ Takafumi Yanagisawa $^{1,3} \cdot$ Hadi Mostafaei ${ }^{1,4} \cdot$ Fahad Quhal $^{1,5} \cdot$ Reza Sari Motlagh ${ }^{1,6} \cdot$ Ekaterina Laukhtina $^{1,7} \cdot$ Nico C. Grossmann ${ }^{1,8}$. Pawel Rajwa ${ }^{1,9}$. Abdulmajeed Aydh ${ }^{1,10}$. Frederik König ${ }^{1,11}$ - Pierre I. Karakiewicz ${ }^{12}$. Motoo Araki ${ }^{2}$. Yasutomo Nasu ${ }^{2}$. Shahrokh F. Shariat ${ }^{1,7,13,14,15,16,17}$}

1 Department of Urology, Comprehensive Cancer Center, Medical University of Vienna, Währinger Gürtel 18-20, 1090 Vienna, Austria

2 Department of Urology, Okayama University Graduate School of Medicine, Dentistry and Pharmaceutical Sciences, Okayama, Japan

3 Department of Urology, The Jikei University School of Medicine, Tokyo, Japan

4 Research Center for Evidence Based Medicine, Tabriz University of Medical Sciences, Tabriz, Iran
5 Department of Urology, King Fahad Specialist Hospital, Dammam, Saudi Arabia

6 Men's Health and Reproductive Health Research Center, Shahid Beheshti University of Medical Sciences, Tehran, Iran

7 Institute for Urology and Reproductive Health, Sechenov University, Moscow, Russia

8 Department of Urology, University Hospital Zurich, Zurich, Switzerland 
9 Department of Urology, Medical University of Silesia, 41-800 Zabrze, Poland

10 Department of Urology, King Faisal Medical City, Abha, Saudi Arabia

11 Department of Urology, University Medical Center Hamburg-Eppendorf, Hamburg, Germany

12 Cancer Prognostics and Health Outcomes Unit, Division of Urology, University of Montreal Health Center, Montreal, Canada

13 Department of Urology, Weill Cornell Medical College, New York, NY, USA
14 Department of Urology, University of Texas Southwestern, Dallas, TX, USA

15 Department of Urology, Second Faculty of Medicine, Charles University, Prague, Czech Republic

16 Karl Landsteiner Institute of Urology and Andrology, Vienna, Austria

17 Division of Urology, Department of Special Surgery, Jordan University Hospital, The University of Jordan, Amman, Jordan 